\title{
PLC ve SCADA Kontrol Yöntemleri ile Sıvı Dolum Otomasyonu
}

\author{
Hilmi Cenk Bayrakçı1 ${ }^{1}$, Hakan Büyükpatpat ${ }^{2 *}$ \\ ${ }^{1}$ Isparta Uygulamalı Bilimler Üniversitesi, Teknoloji Fakültesi, Mekatronik Mühendisliği Bölümü, Isparta, Türkiye, (ORCID: 0000-0001-5064-7310), \\ cenkbayrakci@isparta.edu.tr \\ 2 Bartın Üniversitesi, Mühendislik, Mimarlık ve Tasarım Fakültesi, Bilgisayar Mühendisliği Bölümü, Bartın, Türkiye (ORCID: 0000-0003-3277-8653) \\ hbuyukpatpat@bartin.edu.tr
}

(İlk Geliş Tarihi 8 Şubat 2021 ve Kabul Tarihi 9 Eylül 2021)

(DOI: 10.31590/ejosat.877004)

\begin{abstract}
ATIF/REFERENCE: Bayrakçı, H.C. \& Büyükpatpat, H. (2021). PLC ve SCADA Kontrol Yöntemleri ile Sivı Dolum Otomasyonu. Avrupa Bilim ve Teknoloji Dergisi, (27), 283-291.

\section{Öz}

Endüstriyel üretim için kullanılan sıvı dolum tesisleri insanların ihtiyaçlarını karşılama konusunda önemli bir yer tutmaktadır. Bu üretim tesisleri, endüstriyel otomasyon ve güncel teknolojinin sürekli gelişmesiyle birim zamanda üretim maliyetlerini düşürmektedir. Otomasyon sistemlerinin kontrolünde birçok yöntem olmakla beraber en sık kullanılanlardan biri "Programlanabilir Mantıksal Denetleyiciler (Programmable Logic Controller-PLC)" ile kontrol yöntemidir. PLC'ler işlem hızı, üretim maliyeti, programlama kolaylığı ve bilgi kaynaklarının fazlalığı gibi birçok avantaja sahiptir. PLC'lerle birlikte kullanılan "Merkezi Denetim ve Veri Toplama (Supervisory Control and Data Acquisition-SCADA)" sistemleri verilerin toplanması, izlenmesi, değerlendirilmesi ve operatör kolay kullanımı gibi önemli özelliklere sahiptir. Endüstride kullanılan sıvı dolum ünitelerinin benzer özelliklerine sahip prototip üzerinde çalışmalar yapılmıştır. Bu çalışma prototip sıvı dolum sistemi üzerinde PLC programlaması yapılarak gerçekleştirilmiştir. Dolum tesisi içerisine veri toplama, bilgi sağlama ve uygulama esnasında müdahale için SCADA sistemi dahil edilmiştir. SCADA sistemi bir "İnsan-Makine Arayüz (Human-Machine Interface-HMI)" paneli üzerinden kontrol edilebilmektedir. Prototip sistemde HMI ekranından seçilen ürün ve ağırlıklarına göre bardaklara dolum gerçekleştirilmiştir. Ürün bilgileri kullanıcı tarafından girilmektedir. Kullanıcının girmiş olduğu bilgilerin uygunluğu HMI panel içerisine yazılan makro koduna göre belirlenmektedir. İstenilen dolum sayısına göre bardak deposundan bardaklar çıkarak sıvı dolum istasyonlarına gelir. Sıvı dolumu ağırlık sensör bilgilerinin gerçek zamanlı kontrolü ile gerçekleştirilir. İstenilen miktarda dolum gerçekleştikten sonra bardakların kapakları takılır. Bardak kapaklarının üzerine dolum çeşidine göre etiketleme(sade-karışı) yapılarak çıkışa gönderilir. Üretilen ürünler çıkış istasyonundan alınır. Böylece talep edilen miktar ve oranda ürünler otomasyon sisteminde tam otomatik olarak üretilmiş olur.
\end{abstract}

Anahtar Kelimeler: Sıvı Dolum, PLC, SCADA.

\section{Liquid Filling Automation with PLC and SCADA Control Methots}

\begin{abstract}
Liquid filling facilities used for industrial production have an important place in supply the needs of people. These production facilities reduce production costs per unit time with the continuous development of industrial automation and current technology. Although there are many methods in the control of automation systems, one of the most frequently used is the control method with "Programmable Logic Controller (PLC)". PLC's have many advantages such as processing speed, production cost, ease of programming and very information resources. "Supervisory Control and Data Acquisition (SCADA)" systems used with PLCs have important features such as data collection, monitoring, evaluation and operator ease of use. Studies on a prototype with similar properties of the liquid filling unit used in the industry have been made. This study has been performed by programming PLC on the prototype liquid filling system. A SCADA system is included in the filling facility for data collection, information obtainment and intervention during implementation. The SCADA system can be controlled via a "Human-Machine Interface (HMI)" panel. In the prototype system, the glasses are filled according to the product selected and their weight from the HMI screen. The contents of the product are entered by the user. The conformity of the contents entered by the user is determined according to the macro code written into the HMI panel. Depending on the desired filling number, the glasses leave the glass storage and arrive at the liquid filling stations. Liquid filling is performed by real-time control of weight sensor data. After the desired amount is filled, the cups of the glasses are attached. Labeling (pure-mixed) is made on the glass cups according to the filling type and sent to the exit. The products
\end{abstract}

* Sorumlu Yazar: Bartın Üniversitesi, Mühendislik, Mimarlık ve Tasarım Fakültesi, Bilgisayar Mühendisliği Bölümü, Bartın, Türkiye, (ORCID: 0000-0003-3277-8653) hbuyukpatpat@bartin.edu.tr 
produced are taken from the exit station. Thus, the products in the requested quantity and ratio are produced in the automation system fully automatically.

Keywords: Liquid Filling, PLC, SCADA.

\section{Giriş}

Dolum ve paketleme tesisleri endüstrinin birçok alanında kullanılmaktadır. Bu tesislerden başlıcaları gıda ve kimyasal ürün üretilen yerlerdir. Üretilen ürünlerin istenilen miktarlarda doldurulup paketlenmesi ve birim ürün başına harcanan maliyetin azaltılarak karlılığın yükseltilmesi hedeflenir. Bu hedefin gerçekleştirilmesinde en önemli parçalardan biri otomasyon sistemleridir. Doğru oranlarda doldurulmuş, kaliteli ve hassas ürünlerin üretilmesi için otomasyon sistemi gerekir. Üretim sistemlerinde kullanılan otomatik makineler mekatronik sistemleri ifade eden elektrik-elektronik, mekanik ve bilgisayar disiplinlerini içermektedir. $\mathrm{Bu}$ sebeple otomatik makine ve sistemlerinin hayata geçirilmesinde modüler ve mekatronik tasarım yöntemleri kullanılmaktadır (Hamzaoğlu, 2015).

Literatür incelendiğinde, yapılan bir tez çalışmasında PLC ve SCADA ile sıvı boya dozajlama sistemi gerçekleştirilip performansı incelenmiştir. Endüstriyel boyaların belirlenen oranda karıştırılmasını ve farklı aralıklarda renklendirilmesini sağlayan prototip tasarlanmıştır. Çalışmanın sonunda karışımların doğruluğunun \%97,5 olduğu görülmüştür. Yüksek hassasiyet ve doğruluğun sağlanması otomasyon sistemi ile gerçekleştirilmiştir (Kafalı, 2019).

Çilek (2005), tez çalışmasında PLC ve SCADA sistemleri hakkında genel bilgiler vermiş ve ASKİ İvedik Su Arıtma Tesislerinde uygulama yapmıştır. Uygulama sıvı klor tankları ve 6 tane vanadan meydana gelmiştir. Otomatik tank değiştirme işlemi için tank basınçlarının hazır olup olmadı ̆̆ı, vanaların arıza durumlarının gözlemlenip kontrol edildiği ve sırasıyla devreye alındığı sistemler oluşturmuştur. Yapılan bu işlemler PLC ve SCADA ile kontrol edilmiştir (Çilek, 2005).

Değirmencioğlu (2008), tez çalışmasında yük hücresi (loadcell) sensörü kullanarak elmaların ağırlıklarına göre sınıflandırılması yapmıştır. Sınıflandırma ile elma meyveleri dört ayrı ağırlık grubuna bölünmüştür. Uygulamada sınıflandırma toleransı titreşim etkilerinden dolayı $20 \mathrm{~g}$ olarak belirlenmiştir. Sınıflandırma teknolojisinin geliştirilerek uygulamada $5 \mathrm{~g}$ toleransa kadar ineceği öngörülmüştür (Değirmencioğlu, 2008).

Bayındır vd.(2011), çalışmalarında endüstride kullanılan sıvı depolama tanklarının seviye, basınç ve sıcaklık verilerinin izlenmesi ve meydana gelebilecek sorunlara karşı PLC ile kontrol edilen bir izleme yöntemi (SCADA) önermişlerdir. Yapılan bu çalışma ile endüstriyel sistemin görsel olarak takip edilebilmesi ve olası bir arızanın uyarı mesajlarıyla daha kolay tespit edilebilmesi sağlanmıştır. Yapılan deneysel çalışma ile prototipi geliştirilen sistemin daha az maliyetli, hassas, kararlı ve otomasyon sistemi içermeyen kumanda sistemlerinde kullanılan röleler, kontaktörler, sayıcılar ve dönüştürme kartları kadar güvenilir olduğunu gösterilmiştir (Bayındır vd., 2011).

Becerikli (2013), tez çalışmasında katı ve sıvıların tartım hassasiyetinin arttırılması ve dozajlanması için PLC ve SCADA sistemi kullanmıştır. Sistemde 3 adet ayrı bunker bulunmaktadır. İlk bunkerde açma-kapama ile pnömatik kontrollü ölçüm yapılmış, ikinci bunkerde manuel düzeltme katsayılarıyla pnömatik kontrollü ölçüm yapılmış ve üçüncü bunkerde oransal pnömatik valf ile PID kontrolörle ölçüm yapılarak üç farklı ölçüm sisteminin karşılaştırılması sağlanmıştır. Sistemdeki dozajlama otomatik hale getirilerek endüstriyel sistemlere uygunluk sağlanmıştır (Becerikli, 2013).

Aykaç (2010), tez çalışmasında şeker fabrikalarında kullanılan paketleme ve tartım yapan makinelerin tartım doğruluğunu artırmak amacıyla çuvallardaki fazla şekeri boşaltan ve eksik şekeri ekleyen bir prototip geliştirmiştir. Şeker doldurma işleminde gerekli dolum miktarı istatistiksel analiz ile belirlenmiştir. Doldurma için küresel bir ventil, şekerin emilmesi için vakum kullanılmıştır. Pnömatik bir silindir aracılığıyla haznenin hareketi sağlanmış ve tartı sonuçları loadcell yardımıyla alınmıştır. Sistemin kontrolü PLC ile gerçekleştirilmiş, SCADA arayüzünden kontrol ve izleme için faydalanılmıştır (Aykaç, 2010).

Hamzaoğlu (2015) tez çalışmasında peynir üretim basamağı ve paketleme işleminin gereği olan tuzlama aşaması otomatikleştirme ve üretim zamanından tasarruf sağlanmasını, maliyetin azaltılması ve hijyen koşullarının iyileştirilmesini amaçlamıştır. PLC ile kontrol edilen makinede bilgiler fotoelektrik, endüktif ve seviye sensörleriyle alınmaktadır. $\mathrm{Bu}$ bilgiler PLC'de işlenerek gerekli pompa, valf ve motorlar çalıştırılmıştır (Hamzaoğlu, 2015).

Erol vd. (2015), çalışmalarında PLC ile PI denetleyici kullanılarak gerçek zamanlı sıvı seviye kontrolü yapmışlardır. PI parametreleri gerçek zamanlı olarak sistemin açık çevriminden hesaplanmıştır. Sıvı seviyesine bozucu etki vererek istenen sıvı seviyesini takip edip etmediği gözlemlenmiştir. Eldeki veriler incelendiğinde denetleyici istenen sıvı seviyesini takip ettiği ve yük etkilerine karşı hızlı cevap verdiği görülmüştür (Erol vd., 2015).

Özer (2016), çalışmasında endüstriyel sistemlerde PLC ve SCADA uygulaması yapmıştır. $\mathrm{Bu}$ uygulamada bir prototip sisteme PLC bağlanarak elde edilen veriler SCADA sisteminde takip edilmiştir. Endüstriyel sistemdeki ağırlık, seviye, debi, basınç ve sıcaklık değerleri uzaktan kumanda kontrol altında tutulmuştur. Herhangi bir olumsuzluk durumunda hizlica müdahale edilebilme imkânı oluşturulmuştur (Özer, 2016).

Chakraborty vd. (2020), yaptıkları çalışmada, yarı otomatik bir tesis için bir tankın su seviyesi ve kontrol yönetimini incelemek için PLC yazılımı ve SCADA kullanılmıştır. Sensörlerden gelen bilgi ile su seviyesinin düşük olması durumunda pompa otomatik olarak başlatılmıştır. Düşük ve yüksek su deposu seviyelerinin ölçülmesi, pompanın çalıştırılması, tank suyu seviyesinin doldurulması ve pompanın istenen su seviyesinde durdurulmasını içeren sistem yazılımı PLC merdiven programlaması ile gerçekleşmiştir. SCADA sistemiyle tüm süreç gerçek zamanlı olarak gözlemlenip kontrol edilmiş ve monitör ekranı ile görselleştirilmiştir. Yapılan çalışmada otomasyon teknolojisinin son derece güvenilir, verimli ve tesisin işletme maliyetini azaltmaya yardımcı olduğu görülmüştür (Chakraborty vd., 2020).

Başka bir çalışmada PLC ile yönetilen bir tartılı lizimetre sistemi geliştirilmiştir. Kahramanmaraş koşullarında Maraş 18 tipi ceviz bitkisi üzerinde uygulanmıştır. Sistemdeki lizimetre tankı 5 ton kapasiteli ve 4 adet ağırlık algılayıcısına bağlanmıştır. CODESYS programlama ile lizimetre, yağış ve drenaj miktarının belirlenmesi ve sulama programları adımları hazırlanmıştır. PLC ile sistem otomasyonu gerçekleştirilerek 2018 yılı Haziran-Ekim dönemi süresince toplam ve günlük 
evapotranspirasyon miktarının sırasıyla $261 \mathrm{~mm}$ ve $1.25-3.5 \mathrm{~mm}$ olduğu belirlenmiştir (Gençoğlan vd., 2020).

Literatürde yapılan araştırmalarda görülmüştür ki, sıv1 dolum tesislerinin tasarımı ve uygulamasıyla ilgili çalışmalarda en önemli parametre dolum hassasiyetidir. Bu çalışma ile birebir örtüşen çalışma olmamakla beraber prototip olarak tasarlanan sistemin gerçekleştiriminde kullanılan PLC ve SCADA sistemlerinin benzer kullanımları vardır. $\mathrm{Bu}$ çalışmada otomasyon sistemi içerisinde bulunan PLC ve SCADA kontrolü ile hassas, verimli, doğruluğu yüksek ve hızlı ürün üretimi gerçekleşecektir.

\section{Materyal ve Metot}

\subsection{PLC ve SCADA}

Endüstrinin hemen her yerinde sistem ve cihazların kontrolü için otomasyon sistemleri kullanılır. Endüstride kullanılan otomasyon sistemlerinin büyük çoğunluğu PLC'lerden oluşur. PLC'lerle beraber kullanılan SCADA sistemleri yapilan kontrolün görselleştirilmesi, kullanımının kolaylaştırılması, verilerin toplaması ve izlenmesi gibi özelliklere sahiptir.

\subsubsection{PLC}

PLC giriş ve çıkış verilerinin durumunu sürekli kontrol eden, içerisindeki programa göre kararlar veren ve işlemleri yürütmek için çevre üniteleri olan bir mikroişlemcidir. PLC'lerin içinde verileri işlemek için bir mikroişlemci, işlem esnasında kullanılan verileri saklamak için geçici hafıza ve PLC içerisindeki programları saklamak için de sabit bellek bulunmaktadır. PLC'lerin içerisinde birçok giriş ve çıkış birimleri vardır. Otomasyon sistemi içerisinde kullanılan PLC'nin görseli Şekil 1'de verilmiştir.

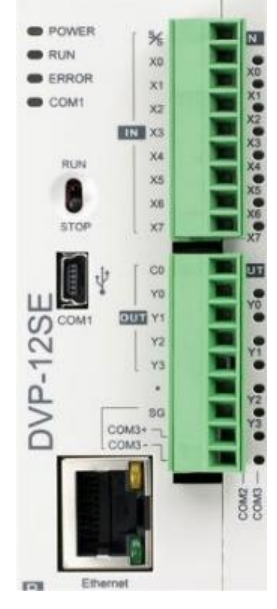

Şekil 1. PLC

PLC'nin endüstride çok kullanılıyor olması birçok üretici ile beraber çok sayıda marka ve modeli beraberinde getirmiştir. $\mathrm{Bu}$ marka ve modeller arasında birçok farklılık olsa da temelde aynı görevi gerçekleştirmek üzere üretilmişlerdir. Üretimdeki bu farklılar işlem hızı, girişs/çıkış sayıları, boyutları, programlama yöntemleri, fiyatları, dahili modülleri gibi özellikleri içermektedir. Aynı marka PLC içerisinde de yıllar geçtikçe geliştirme yapılmakta ve bir önceki sürümüne göre yenilikler eklenmektedir.

Sıvı dolum otomasyon sistemi içerisinde kullanılan PLC Delta marka DVP12SE-11T serisidir. Kullanılan PLC'nin özellikleri Tablo 1'de verilmiştir.
Tablo 1. Kullanılan PLC'nin Özellikleri

\begin{tabular}{|l|c|}
\hline Program Kapasitesi & 16k Step \\
\hline $\begin{array}{l}\text { Maks. Giriş-Çıkış } \\
\text { Sayısı }\end{array}$ & 480 Adet \\
\hline Hızlı Giriş Sayısı & $\begin{array}{r}\text { 2 Adet } 100 \mathrm{KHz} \\
6 \text { Adet } 10 \mathrm{KHz}\end{array}$ \\
\hline Hızlı Çıkış Sayısı & $\begin{array}{r}2 \text { Adet } 100 \mathrm{KHz} \\
2 \text { Adet } 10 \mathrm{KHz}\end{array}$ \\
\hline Haberleşme & 2 Adet RS485 \\
& Mini USB-Ethernet \\
\hline Sol Modül Desteği & Mevcut \\
\hline Çıkış Birimi & Transistör \\
\hline
\end{tabular}

PLC'nin programlamasında kullanılan çeşitli ve farklı yapılarda yazılım dilleri vardır. PLC programlamada kullanılan yazılım dilleri; Merdiven Diyagramı (Ladder Diagram-LD), Yapisal Metin (Structured Text-ST), Komut Listesi (Instruction List-IL), Siralı Fonksiyon Tablosu (Sequential Function ChartSFC) ve Fonksiyon Blok Diyagramı (Function Block DiagramFBD) 'dır (Eminoğlu, 2013). Bu programlama dilleri aynı amaca hizmet eden ama görselleştirilmesi ve yazılması farklı olan yapılardır. PLC ile otomasyon sistemi yapılırken en sik kullanılan programlama dilinden biri olan merdiven diyagramı anlaşılması ve programlaması kolay bir yapıya sahiptir. $\mathrm{Bu}$ yazılım dili sıvı dolum sisteminin PLC ile programlanmasında kullanılmıştır. Sıvı dolum sisteminin PLC programı içerisinden merdiven diyagramı akışını gösteren örnek bir yapı Şekil 2'deki gibidir.

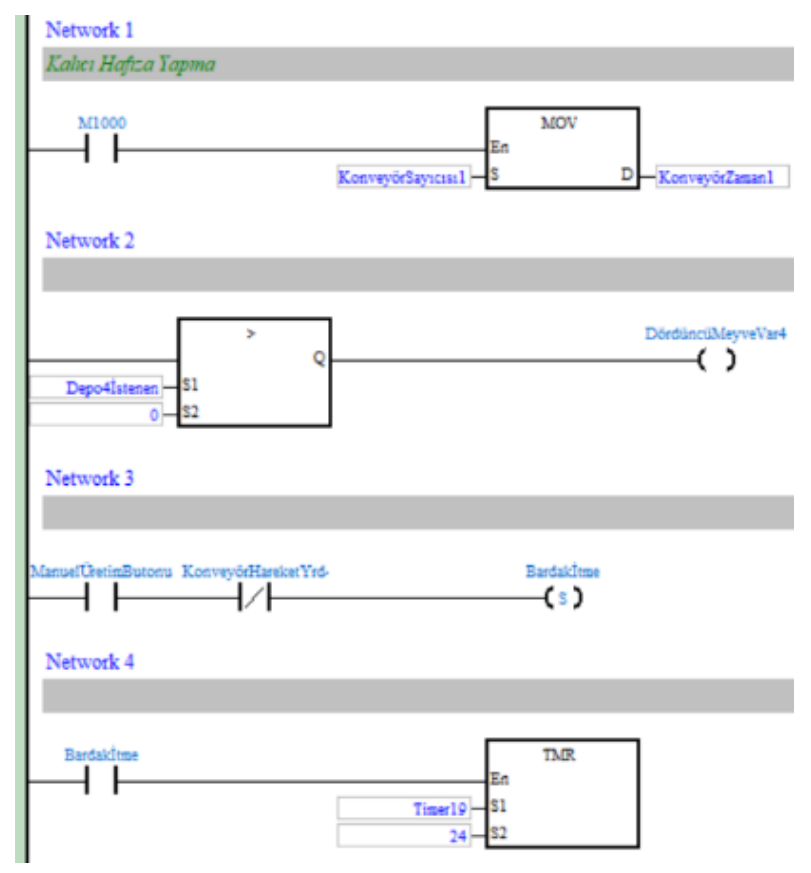

Şekil 2. Merdiven Diyagramı

PLC programlamasında merdiven diyagramının kullanımı oldukça basit olmasına rağmen giriş-çıkış sayısının fazlalığı, yardımcı kontak kullanımı ve sayıcı-zamanlayıcı modüllerinin kullanımı çok fonksiyonlu bir programda karmaşıklığa sebep olabilmektedir. $\mathrm{Bu}$ karışıklığı önlemek için bütün yapısal nesnelere isim vermek gerekir. Bu isim ve adreslerin tutulduğu yer Sembol Tablosu'dur. Sembol tablosunun oluşturulması karışıklığı önlemekle beraber programlama yapılırken kolaylık sağlamaktadır. Sıvı dolum sisteminin PLC programı içerisindeki sembol tablosunu gösteren örnek bir yapı Tablo 2'deki gibidir. 
Tablo 2. Sembol Tablosu

\begin{tabular}{|c|c|c|c|}
\hline Identifiers & Address & Type... & Initial Value \\
\hline KonveyörSayıcısı1 1 & $\mathrm{C} 70$ & COUNTER & N/A \\
\hline KonveyörSayıcıs12 & C71 & COUNTER & N/A \\
\hline Depo1Ölçülen & D23 & WORD & 0 \\
\hline Karıș1k listenen & D5 & WORD & 0 \\
\hline Karıș1k 2 istenen & D6 & WORD & 0 \\
\hline BirinciMeyveVar & M21 & BOOL & FALSE \\
\hline İkinciMeyveVar & M22 & BOOL & FALSE \\
\hline Meyve1 & M41 & BOOL & FALSE \\
\hline Timer1 & $\mathrm{T} 1$ & TIMER & $\mathrm{N} / \mathrm{A}$ \\
\hline Timer2 & $\mathrm{T} 2$ & TIMER & N/A \\
\hline BardakSensörü & $\mathrm{X} 30$ & BOOL & FALSE \\
\hline BaşlangıçSensörü & $\mathrm{X} 31$ & BOOL & FALSE \\
\hline StepMotor & Y0 & BOOL & FALSE \\
\hline StepMotorYön & Y1 & BOOL & FALSE \\
\hline DördüncüVakum & Y20 & BOOL & FALSE \\
\hline ÜçüncüVakum & Y 21 & BOOL & FALSE \\
\hline ÜçünçüA ğırliğaIttme & Y 22 & BOOL & FALSE \\
\hline İkinciAğırlığaİtme & Y23 & BOOL & FALSE \\
\hline
\end{tabular}

\subsubsection{SCADA}

SCADA genel sistem içerisindeki bilgilerin toplanması, izlenmesi, değerlendirilmesi ve kontrolü gibi önemli özellikleri içerisinde bulundurur. PLC ile programlanmış sistemlerin görselleştirilmesi kullanımını kolaylaştırmaktadır. SCADA sistemi 3 ana birimden oluşmaktadır (MEGEB, 2014). Bunlar:

- Kontrol Merkezi (MTU)

- İletişim Sistemi

- Uzak Uç Birimi (RTU)

Merkezi kontrol veya merkezi terminal olarak isimlendirilen MTU, yerel ağ (LAN) ile veya geniş alan ağ sunucu veya bir grup cihazın ana sunucuya bağlanmasıdır. $\mathrm{Bu}$ çalışmada merkezi kontrol birimi PLC ile yapılmıştır.

Uzak uç birimleri SCADA tarafindan kontrol edilen ve izlenen cihaz veya makinelere bağlı olan ekipmanlardan oluşur. Uzak uç birimleri, merkezi kontrol istasyonuna göndermek üzere sensörlerden gerçek zamanlı bilgileri alır. Ayrıca ana istasyondan gelen bilgileri alarak gerekli işlemleri yürütür. Çalışmada bu görevleri yerine getirmesi için HMI ekran cihazı kullanılmıştır.

SCADA sistemlerinde, kontrol merkezi ile bir veya birden fazla uç birimleri arasında iletişim kurmak için haberleşme protokolleri kullanılır. SCADA sistemlerinde siklıkla kullanılan haberleşme protokolleri Modbus, Profinet, TCP/IP ve DNP3 'dür. Bu çalışmada MTU ile RTU arasında TCP/IP iletişim protokolü kullanılmıştır (Şeker, 2019).

SCADA sistemi içerisinde hem yazılımı hem de donanımı barındıran önemli kullanım araçlarıdır. SCADA endüstride prosesin olduğu tesisler (gıda, çimento, ilaç, boya), enerji, trafik, doğalgaz, nükleer vb. alanlarda sıklıkla kullanılırlar. SCADA sisteminin genel çalışma mimarisi Şekil 3 'te verilmiştir.

Yapılan çalışma içerisinde kullanılan SCADA sisteminin uzak uç birimi HMI paneldir. HMI paneller endüstriyel tesislerde cihaz ve makinelerin takibi, kullanımı ve yönetilmesi görevlerinde operatör veya kullanıcılara kolaylık sağlar.

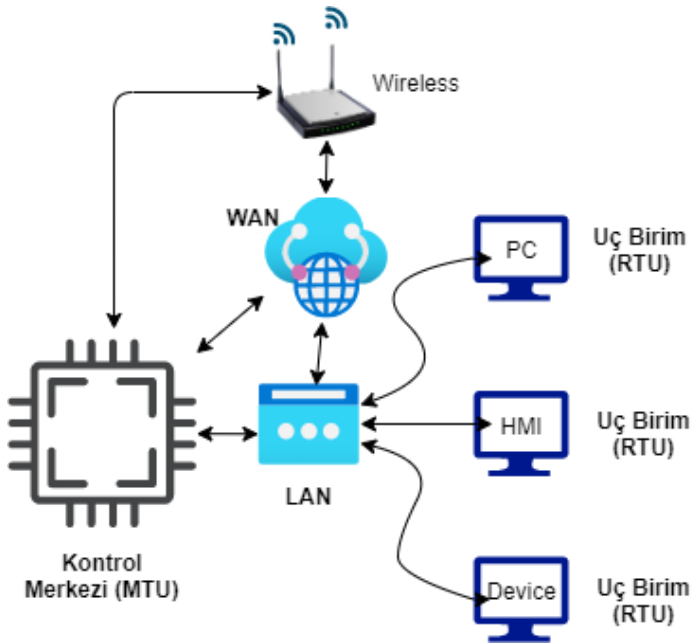

Şekil 3. SCADA Mimarisi

Çalışmada sıvı dolum işlemi için üretim miktarına göre üretim yönteminin belirlenmesi gerekmektedir. Sivı dolumu yapılacak ürün miktarı 1'den fazla ise HMI paneldeki ilgili ekrandan otomatik buton seçimi yapılır. Bu işlemin yapılması için tasarlanan ilgili HMI ekranı Şekil 4'te verilmiştir.

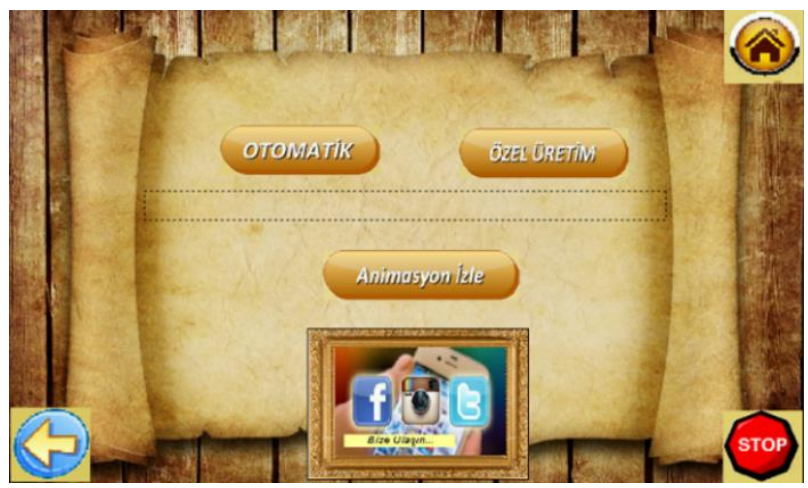

Şekil 4. Üretim Yöntemi Seçim Ekranı

Fazla adette sıvı dolumu için kullanılan otomatik üretim ekranı içerisinde seçilebilecek 4 adet farklı ürün bulunmaktadır. $\mathrm{Bu}$ ürünlerden biri veya birkaçı seçilerek gramajları belirlenir. Ürün özelliklerinin belirlenmesiyle kaç adet üretileceği girilir. Maksimum üretim adedi maksimum bardak kapasitesi ile doğru orantılıdır ve varsayılan olarak 10 adet ile sınırlandırılmıştır. Tasarlanan ekran görüntüsü Şekil 5’te verilmiştir.

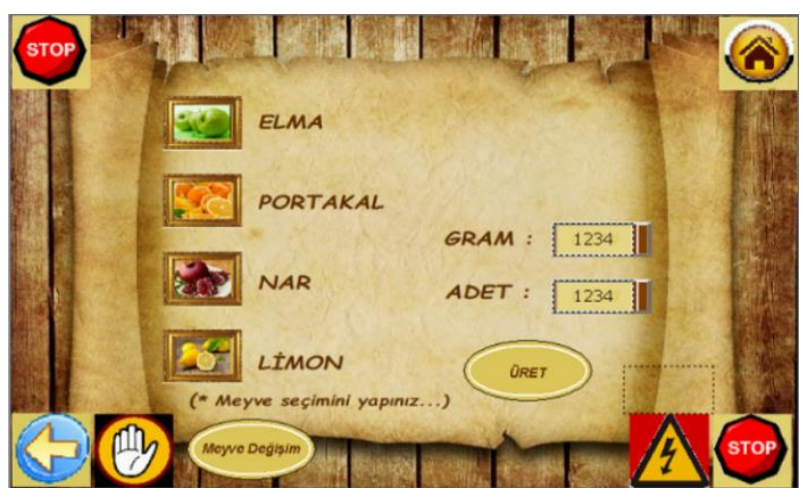

Şekil 5. Otomatik Ürün Üretim Bilgi Giriş Ekranı

HMI ekranından ürün bilgilerinin girişinin yapıldığı sırada bazı kontroller için arka planda makro kodları yazılmıştır. Bu makrolardan biri maksimum bardak limitinin aşılmaması için kullanılmaktadır. Üretimde kullanılan örnek bir makro kodu Şekil 6‘da gösterilmiştir. 


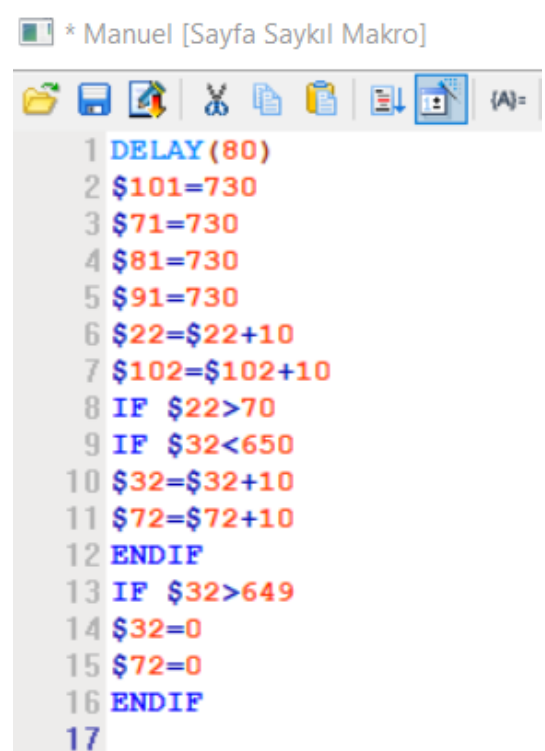

\section{Şekil 6. Ürün Üretim Limiti Makro Kodu}

Ürün üretimi için çalışan birden fazla prosesin adetli üretimde uyumlu çalışması gerekmektedir. Sıvı dolum sistemi içerisinde çalışan otomatik üretim yöntemi endüstride kullanılan otomasyon sistemine benzer yapıda çalı̧̧maktadır. Endüstriyel sıvı dolum tesislerinin çalışma yapısına ek olarak bu çalışmada kullanıcıya özel üretim metodu geliştirilmiştir. Kullanıcının istediği üründen istediği oranda karıştırma yapmasına imkân verilmiş̧ir. Şekil $7^{`}$ de gösterilen özel üretim ekranında proses içerisinde çalışan sıvı depolarının seviyelerini gösteren baremler konulmuştur. Her ürünün altına miktar girilmesi için giriş ünitesi yerleştirilmiştir. Seçimlerin yapılması ile üretim butonuna basılarak sıv1 dolum sistemi kullanıcı tarafindan çalıştırılabilmektedir.

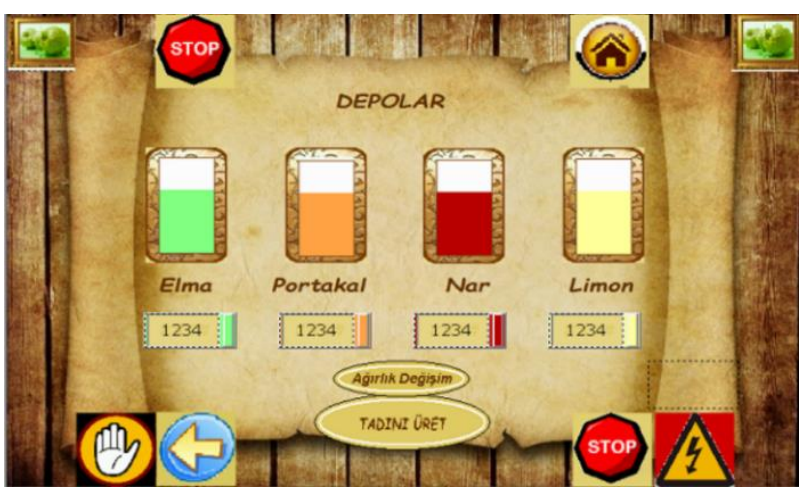

Şekil 7. Özel Üretim Bilgi Giriş Ekranı

Üretimin gerçekleştiği esnada veya bitişinde sistem içerisinde kullanılan sıvı, bardak ve kapak gibi harcanan ürünler bitebilmektedir. Sistem içerisinde herhangi bir ürün bittiğinde üretim durur ve sistem alarm verir. Biten ürünlerin sıvı dolum sistemi yöneticisi veya operatörü tarafindan tamamlanması için bir ekran programlanmıştır. Ürünlerin tamamlaması ardından yönetici veya operatör Şekil 8‘deki ekrandan alarm kaldırma işlemini yapar.

SCADA ekranlarında genel kontrolün sağlanması için acil durum butonu, malzeme bitiş butonu, önceki ve ana sayfaya dönme çubukları konmuştur. Ekranda ürünlerin anlaşılmasını ve kullanıcının bilgilendirilmesini sağlayan yazılar ve kayan resimler bulunmaktadır.

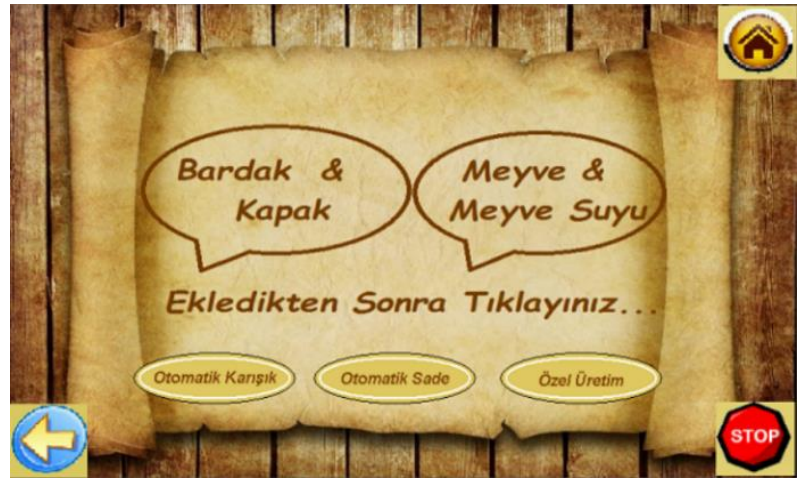

Şekil 8. Ürün Ekleme Kontrol Ekranı

\subsection{Sistem Bileşenleri}

Çalışma içerisinde kullanılan giriş (sensör, sayısal veri) ve çıkış (motor, valf, alarm) elemanları proseslere göre farklıklar göstermektedir. Sistem içerisinde ana dört adet proses kullanılmaktadır. Ana proseslerin içerisinde ana proses işleminin tamamlanması için birçok yardımcı proses bulunmaktadır. Tüm prosesler önceki bölümde anlatılan PLC ve SCADA yazılımı tarafindan kontrol edilmektedir.

\subsubsection{Sivı Dolum Prosesi}

Kullanıcıların girmiş olduğu ürün bilgilerine göre seçili ürünlerin bardaklara doldurulma işlemidir. Doldurma işlemi bir sıvı deposundan pnömatik vananın kontrolü ile yapılmaktadır. Sıvı dolum prosesinin gerçekleştirilmesi için sıvı deposunda ürün olması gerekmektedir. Sıvı deposundaki ürün kontrolü için yardımcı proses olan sıvı seviye kontrol prosesi çalışmaktadır. $\mathrm{Bu}$ proseste tankların seviyelerinin ölçümü için basınç transmitleri kullanılmaktadır. Basınç transmitteri $0-250 \mathrm{mBar}$ basınç ölçüm aralığına sahiptir. Basınç sensörü uygulanan basınca göre 4-20 mA veya $0-10 \mathrm{~V}$ arasında analog çıkış üretmektedir. Sensörün görseli Şekil 9a'da verilmiştir.

Basınç transmitterin çıkış sinyalinin analog olması PLC girişine analog sinyal uygulanması demektir. PLC üzerinde dahili olarak gelen giriş çıkış pinleri dijitaldir. Analog olarak gelen giriş sinyalini dijitale çevirmek veya dijital olarak uretilen sinyali analog sinyal çıkışına çevirmek için analog-dijital dönüştürücü kullanılır. Sıvı seviye ölçümü için analog sinyali dijitale çeviren 4 kanallı DVP04AD-S PLC ek modülü kullanılmıştır. Ek modülün görseli Şekil 9b`de verilmiştir.

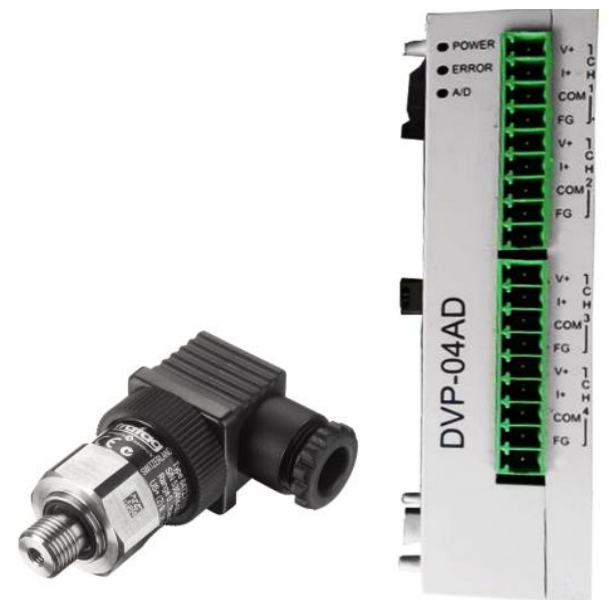

Şekil 9a. Basınç Trasmitteri b. DVP04AD-S Analog Modül

Sıvı seviye ölçümünün istenilen düzeyde olması ve dolum sinyalinin gelmesi ile pnömatik vanalar açlır. Pnömatik 
vanaların kontrolü için elektropnömatik valfler kullanılmıştır. Valflerin elektrik kontrolü kısmına gelen $24 \mathrm{v}$ veya $0 \mathrm{v}$ sinyallerine göre pnömatik hat kaynağı yer değiştirir. Bu sayede valfe verilen sinyal ile vanalar açık kapalı konuma hızlı bir şekilde getirilir.

Dolum işlemi başladığında bardak ağırlığ 1 artacaktır. Bardak istenen ağırlığa geldiğinde vananın kapatılması için ağırlık ölçüm prosesi çalıştırılır. Gerçek zamanlı olarak gerçekleşen bu işlemler yük hücresi (loadcell) adı verilen sensör ölçümü ile ağırlık elde edilir. Yük hücreleri kuvveti elektrik sinyallerine çeviren sensörlerdir. Yük hücrelerinin metallerindeki esneme miktarı gerinim ölçerler(strain-gauge) yardımıyla algılanarak elektriksel direnç değerine dönüştürülür. Yük hücresi sensörü üzerine uygulanan basınca göre analog çıkış üretir (Yaşar, 2020). Yük hücresinin hassasiyeti $\% 1$ olarak verilmiş ve görseli Şekil $10 a^{\text {‘d }}$ verilmiştir. Ölçüm sonuçlarının dijital dönüşümünün sağlanması ve verilerin alınması için DVP02LC serisi loadcell ek modülü kullanılır. Loadcell modülü iki adet yük hücre sensör verisini okuyup işleyebilecek 2 adet kanala sahiptir (Şekil 10b).
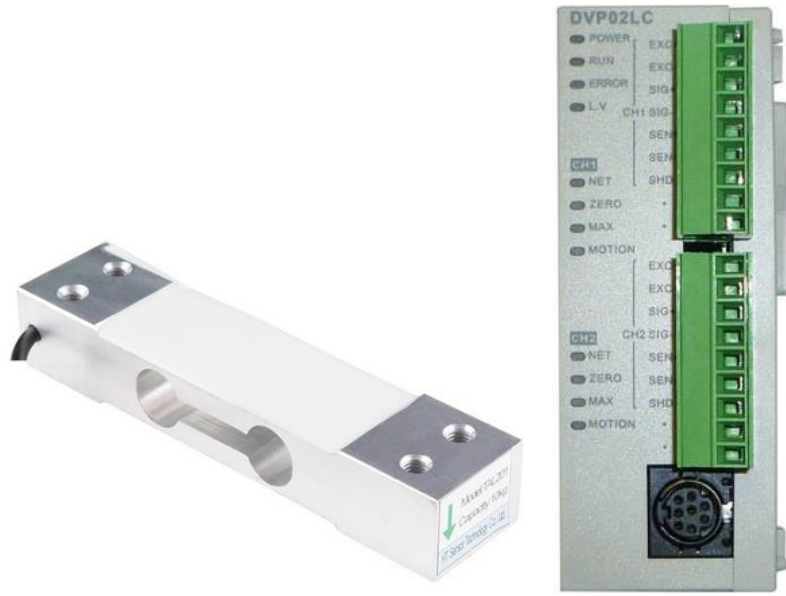

\section{Ssekil 10a. Yük Hücresi b. DVP02LC Loadcell Modülü}

Gerçek zamanlı ağırlık ölçümünde hassasiyetin arttırılması için loadcell modülünün ve yük hücresi sensörünün kalibrasyon ayarlarının yapılması gerekmektedir. Kalibrasyon ayarları ağırlı̆̆ 1 bilinen bir nesne ile gerçekleştirilir. Kalibrasyon işleminin yapıldığı LCSoft arayüzünden örnek program Şekil 11 'de verilmiştir.

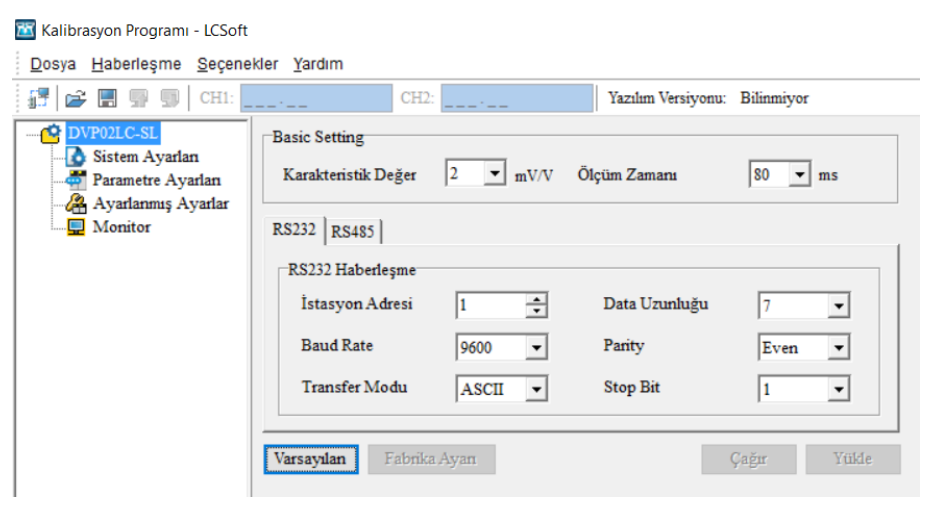

\section{Şekil 11. Kalibrasyon Işlemi}

Sıvı dolum ana prosesi içerisindeki yardımcı prosesler işlemlerini tamamladıktan sonra ana prosese bilgi gönderir. Bütün yardımcı proses bilgileri geldiğinde ana proses işlemleri yürütülür ve tamamlanır. Ana veya yardımcı proseslerin gerçekleştirildiği sırada herhangi bir problem oluşması halinde otomasyon sistemi uyarı verir. Verilen uyarıya göre gerekli düzenlemeler yapılır ve işlemlere kaldığı yerden devam etmesi sağlanır. Başarılı olarak tamamlanan sıvı dolum prosesinin ardından kapak takma prosesine geçilir.

\subsubsection{Kapak Takma Prosesi}

Sıvı dolumu yapılmış olan bardakların kapaklarının takılması için yürütülen ana prosestir. Kapak deposundan kapak vakum yöntemi ile alınır ve bardağın olduğu konuma taşınır. Kapağın taşınması işlemi pnömatik milsiz silinir ile gerçekleştirilir. Milsiz silindirin hareket uzunluğu $500 \mathrm{~mm}$ ve kapak takma yüksekliği $50 \mathrm{~mm}$ 'dir. Kapak takma prosesinin adımları aşağıdaki gibi gerçekleştirilir:

1. Adım: Kapak takma istasyonuna bardak gelir.

2. Adım: Kapak deposundan kapak taşıma yerine itilir.

3. Adım: Taşıma yerinden kapak vakum yöntemi ile alınır ve bardak konumuna götürülür.

4. Adım: 50 milimetrelik dikey eksen hareketiyle kapak takılır.

5. Adım: Milsiz silindir ve vakum başlangıç konumuna döner.

Kapak takma işlemi esnasında işlem adımlarının biri veya birkaçında hata olması halinde prosesin tüm işlemleri baştan başlar. Bütün işlem adımları doğru bir şekilde tamamlandığında ana proses başarı ile tamamlanır. Kapak takma prosesinin tamamlanmasının ardından etiketleme prosesine geçilir.

\subsubsection{Bardak Etiketleme Prosesi}

Bardak üzerinde gerçekleşen son ana prosestir. Sıv1 dolumunun tamamlanmasıyla kapak takma işlemi gerçekleştirilir. Etiketleme yapılırken kullanıcının seçmiş olduğu ürünlerin miktarına göre karışık veya sade etiketi makine logosuyla beraber kapak üzerine basılmaktadır. Birden fazla ürün seçilip istenilen oranlarda karıştırılmasıyla karışık bir ürün içeriği elde edilir. Bu seçim sonucuna istinaden karışık etiketi basılır. Tek ürün seçimi yapılması durumda seçim miktarından bağımsız olarak sade etiketi basılmaktadır. Sade ve karışık etiketlerin logolarıyla birlikte görüntüleri Şekil 12‘de verilmiştir. İşlemleri tamamlanmış olan ürünler çıkışa aktarılır. Ürünler kullanıcı veya operatör tarafından çıkış istasyonundan alınır.

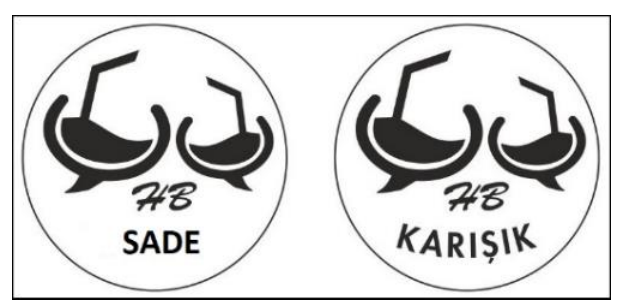

Şekil 12. Sade-Karışık Etiket

\subsubsection{Konveyör Bant Kontrolü}

Bütün ana proseslerin içerisinde bardağın bir konumdan diğer bir konuma taşınması işlemi konveyör bant ile sağlanmaktadır. Konveyör bant bir step motor (86HS45) ile hareket ettirilmekte ve kontrolü için sürücü (M542) kullanılmaktadır. Konveyör bandın hareket etmesi için step motorun konveyör tamburuna tahrik vermesi gerekmektedir. Step motorun dönüşündeki atacağı tur sayısı PLC tarafından pals sinyalleri gönderilerek belirlenir. Step motor bir tur attığında konveyör bandın alacağı yol uzunluğuna göre pals sinyallerinin miktarı ayarlanır. 
Step motorun iç yapısı incelendiğginde açık çevrim kontrollü çalıştı̆̆ görülmektedir. Açık çevrim kontrolde çıkış birimi verisi giriş birimine etki etmez (Şekil 13a). Giriş biriminde verilen pals sayısının çıkışta alınan pals sayısına eşit olup olmadığının kontrolünün yapılmaması bazı durumlarda sorun yaratmaktadır. Örneğin motorda sıkışma olması, konveyör bandın hareket etmemesi veya bant ile motor arasında güç aktarımını sağlayan konveyör tamburlarında problem olması gibi durumlardır. Step motora dön sinyali verildiğinde oluşabilecek hata durumlarından dolayı konveyör bant hareket etmese bile hareketin sağlandığı yanlışı ortaya çıkacaktır. Bu gibi durumların önüne geçmek için kapalı çevrim kontrol yapılır. Kapalı çevrim kontrolde çıkış sinyali ile giriş sinyali karşılaştırılır (Şekil 13b). Karşılaştırma sonucundan çıkan değerler kontrol elemanına hata sinyali olarak giriş yapar. Kontrolör tarafından gerekli işlemler yürütülerek hata sinyalinin sıfır'a düşürülmesi hedeflenir.

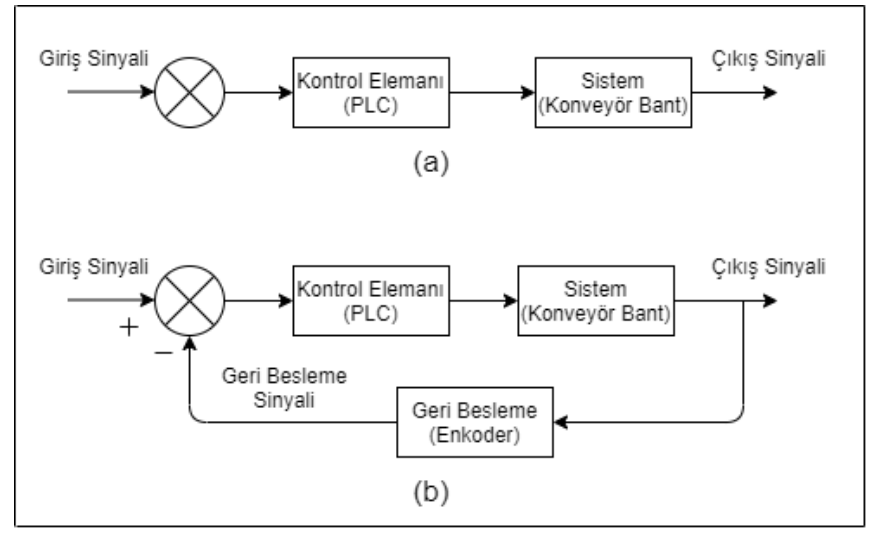

Şekil 13a. Açık Çevrim Kontrol b. Kapalı Çevrim Kontrol

Kapalı çevrim kontrol yapan hareket sistemleri olmakla beraber step motorların da kapalı çevrim kontrolü ile çalıştırılmasının yöntemleri vardır. $\mathrm{Bu}$ yöntemlerden biri step motorun dönen mil ekseni üzerine enkoder bağlamaktır. Enkoder ucundaki milin dönüşü ile dijital veya analog sinyal üreten elektromekanik cihazdır.

Konveyör bant tahrik ve gergi tamburu etrafina geçirilmiştir. Tahrik tamburu motorun bağlı olduğu yeri, gergi tamburu ise bandın gerginliğini sağlayan yeri ifade eder. Konveyör bandın step motorla hareketinin kapalı çevrim ile kontrolü için enkoderin mili dairesel dönüş yapan gergi tamburuna bağlanır (Şekil 14). Motor dönüşü ile bant hareket eder ve gergi tamburu da döner. Dönen gergi tamburundan enkoder sayesinde sinyal alınarak kontrol elemanına gönderilir. Gerçek zamanlı karşılaşırma ile kapalı çevrim kontrol sağlanır. Bardağın bir konumdan başka bir konumuna hareketi için sinyal gönderildiğinde step motor veya konveyör bant sebebiyle hareket sağlanmazsa enkoder bilgi sinyali ile hatalar tespit edilir.

\section{Sıvı Dolum Sistemi}

\subsection{Akış Diyagramı}

Akış şeması sistem algoritmasının görsel elemanlar kullanılarak oluşturulmasıdır. Bir işin tamamlanması için gerekli olan adımların çok daha iyi anlaşılmasını sağlayan görselliği içerir. Algoritma adımlarında belirlenen bir veya daha çok işlem geometrik şekillerle ifade edilir. Bu şekiller belirli standartlara sahiptir. Sıvı dolum sisteminin akış diyagramı Şekil $15^{\prime}$ te verilmişsir.

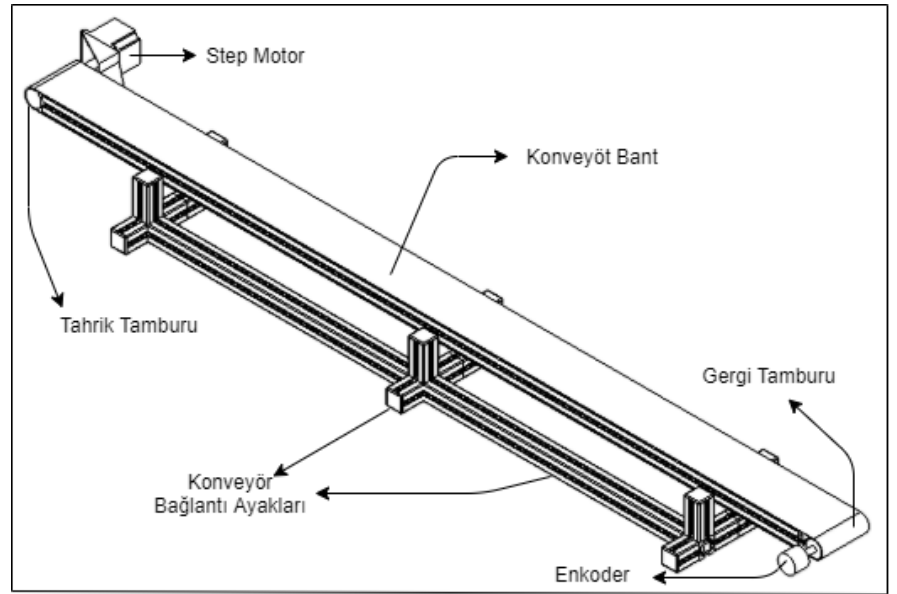

Şekil 14. Konveyör Bant Bileşenleri

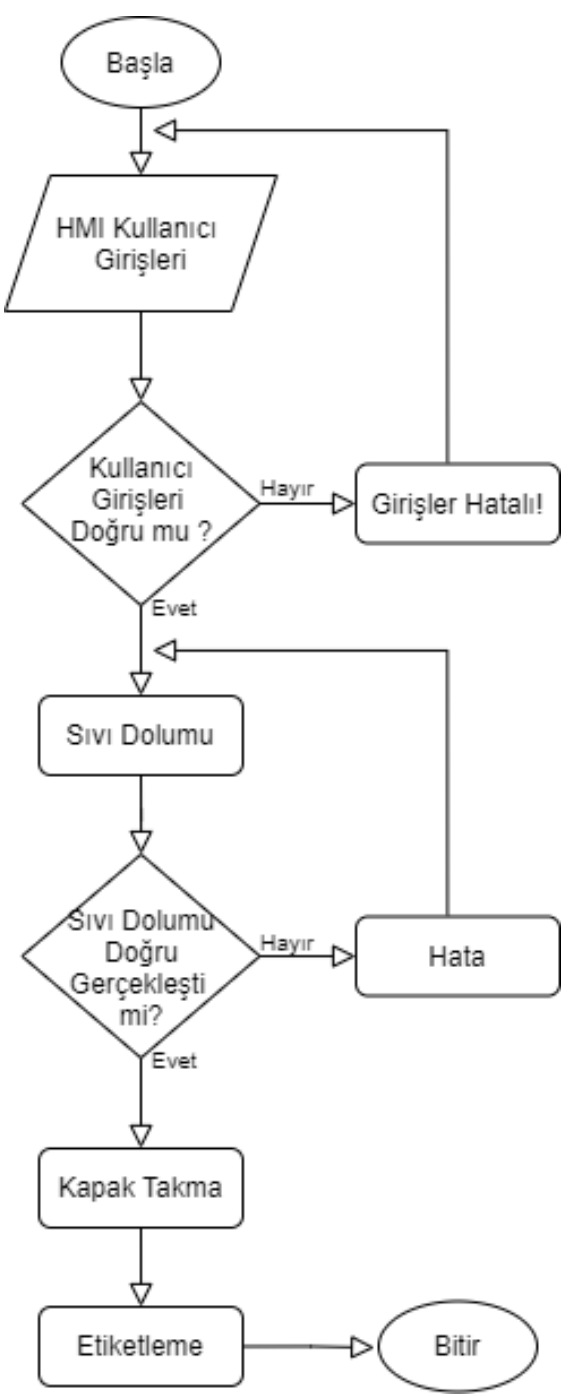

Şekil 15. Akış Diyagramı

\subsection{Sistem Mimarisi}

Sistem mimarisi genel tasarımı veya sistemin yapısını tanımlamak için kullanılır. Teknolojide fiziksel cihazlar geniş bir alanı kapsayacak şekilde genişletildi gibi, bir yöntem organize etmek ve birlikte uyumlu bir şekilde bu öğeleri bağlamakta önemli olacaktır. Yapılan sıvı dolum tesisi için genel mimari yapı Şekil 16'da verilmiştir. 


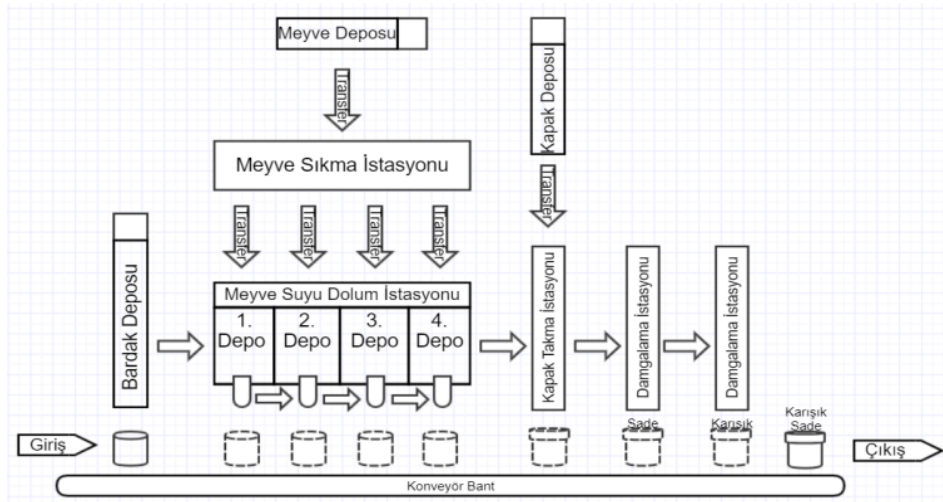

Şekil 16. Sistem Mimarisi

\subsection{Sivı Dolum Otomasyonu Prototipi}

Prototip üzerindeki elektriksel cihaz ve bağlantıların bir kısmı panonun içerisine yerleştirilmiştir. Pano içerisinde kullanılan endüstriyel ekipmanlar PLC, ek modüller, güç kaynağı, sigorta, kaçak akım rölesi, klemensler, step motor sürücüsü ve kablolardır. Sıv1 dolumu esnasında prototip sistemden bilgi alınması ve kullanıcı girişlerinin programa dahil edilmesi için pano dişına elektriksel cihazlar yerleştirilmiştir. $\mathrm{Bu}$ cihazlar, sensörler, step motor, HMI ekran ve kablolardır. Sıvı dolum sisteminin elektrik panosu Şekil 17'de verilmiştir.

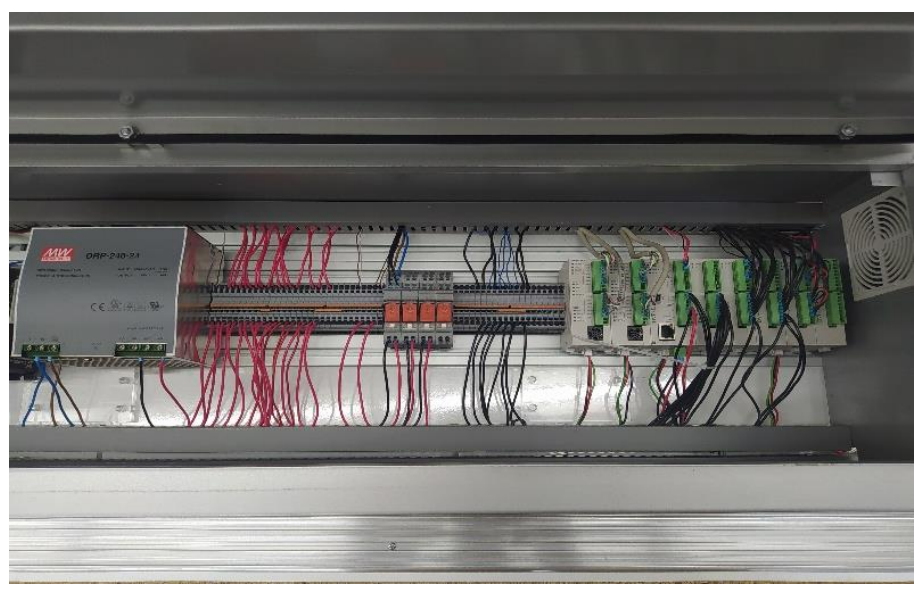

Şekil 17. Elektriksel Bağlantı Panosu

PLC ve SCADA ile sıvı dolum uygulamasının yapıldığı prototip Şekil 18 'de verilmiştir.

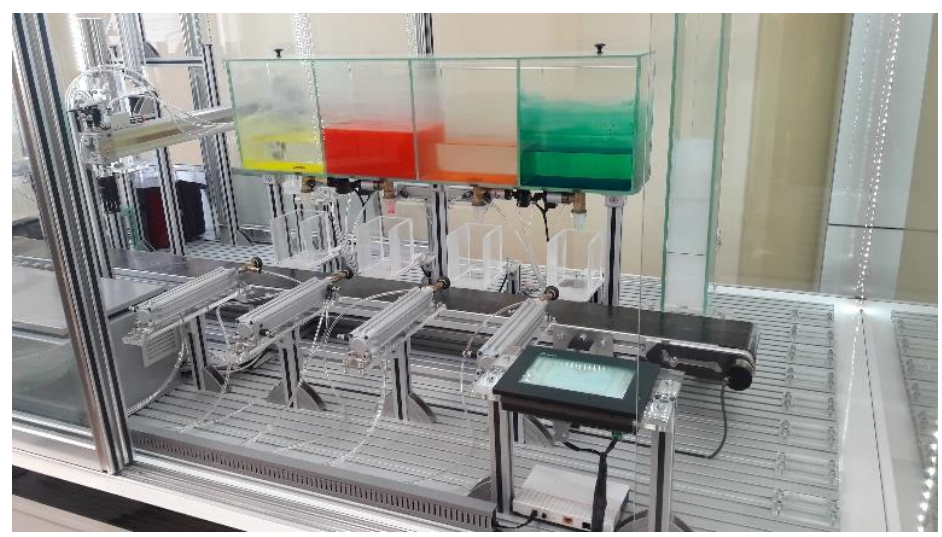

Şekil 18. Sistem Prototipi

\section{Sonuçlar}

$\mathrm{Bu}$ çalışmada endüstride kullanılan sıvı dolum tesislerine benzer özellikte olan bir sıvı dolum prototipi üzerinde PLC ve SCADA uygulamaları yapılmıştır. Gerçekleştirilen çalışmada PLC'lerin işlem hızı, üretim maliyeti, programlama kolaylığı ve bilgi kaynaklarının fazlalığı ile SCADA sistemlerinin verilerin toplanması, izlenmesi, değerlendirilmesi ve operatör kolay kullanımı gibi avantajlarından yararlanılmıştır. SCADA sisteminin kontrolünde HMI operatör paneli kullanılmış ve kullanıcı girişlerinin bu panel üzerinden yapılması sağlanmıştır. Kullanıcıların istediği miktarda ve oranda ürünlerin üretimi için gerekli yazılımlar yapılmıştır. Sıvı dolum sistemi içerisinde gerçekleştirilen ana uygulamalar dolum, kapak takma ve etiketleme olmuştur. $\mathrm{Bu}$ ana uygulamalar içerisinde farklı yardımcı uygulamalar kullanılmış ve ana uygulama gerçekleştirimi sağlanmıştır. Üretim esnasında meydana gelebilecek herhangi bir probleme karşı düzeltme senaryoları geliştirilmiştir. Çalışmanın daha sonra bu konuda çalışabilecek araştırmacılara ve ilgili sektördeki imalatçılara rehber olabileceği düşünülmektedir.

\section{Kaynaklar}

Aykaç, E. S. (2010). Development of a SCADA Control System for a Weighing and Bagging Machine. Master Thesis, Middle East Technical University Department of Mechanical Engineering, Ankara.

Bayındır, R., Kaplan, O., Bayyiğit, C., Sarıkaya, Y., \& Hallaçlığlu, M. (2011). PLC ve SCADA Kullanılarak Bir Endüstriyel Sistemin Otomasyonu. Erciyes Üniversitesi Fen Bilimleri Enstitüsü Fen Bilimleri Dergisi, 27(1), 107115. https://dergipark.org.tr/en/pub/erciyesfen/issue/25571/269 745

Becerikli, F. (2013). PLC ve SCADA Sistemlerinde Katı ve Siviların Tartım Hassasiyetinin Arttırlması ve Dozajlanması. Yüksek Lisans Tezi, Frrat Üniversitesi Fen Bilimleri Enstitüsü, Elazı̆̆.

Chakraborty, K., Choudhury, M. G., Das, S., \& Paul, S. (2020). Development of PLC-SCADA Based Control Strategy for Water Storage in a Tank for a Semi-automated Plant. Journal of Instrumentation, 15(4). https://doi.org/10.1088/1748-0221/15/04/T04007

Çilek, A. (2005). PLC (Programlanabilir Lojik Kontrol Cihazl) ve SCADA (Yönetsel Denetim ve Veri Toplama) ile Endüstriyel Otomasyon Uygulaması. Yüksek Lisans Tezi, Gazi Üniversitesi Fen Bilimleri Enstitüsü, Ankara.

Değirmencioğlu, G. (2008). A ğırlık Duyarlı Elma Sınıflandırma Otomasyonunun Tasarımı ve Prototip Imalatı. Yüksek Lisans Tezi, Süleyman Demirel Üniversitesi Fen Bilimleri Enstitüsü, Isparta.

Eminoğlu, Y. (2013). PLC Programlama ve S7 1200. Birsen Yayınevi.

Erol, F., Emren, M., Öztürk, S., \& Kuncan, M. (2015). PI Denetleyici ile Sıvı Seviye Kontrolünün Gerçek Zamanlı Olarak PLC İle Gerçeklenmesi. Otomatik Kontrol Ulusal Toplantısl, 10-12.

Gençoğlan, C., Usta, S., \& Gençoğlan, S. (2020). Programlanabilir Lojik Kontrolör (PLC) Tarafindan Yönetilen Bir Tartılı Lizimetre Sisteminin Geliştirilmesi. Mediterranean Agricultural Sciences, 33(1), 107-115. https://doi.org/10.29136/mediterranean.667338 
Hamzaoğlu, S. (2015). Sepet Yıkama ve Salamura Dolum Makinası. Yüksek Lisans Tezi, İstanbul Teknik Üniversitesi Fen Bilimleri Enstitüsü, İstanbul.

Kafalı, A. (2019). PLC ve SCADA Tabanlı Sivı Boya Dozajlama Sisteminin Gerçekleştirilmesi ve Performansının Incelenmesi. Yüksek Lisans Tezi, Necmettin Erbakan Üniversitesi Fen Bilimleri Enstitüsü, Konya.

MEGEB. (2014). Endüstriyel Otomasyon Teknolojileri, SCADA Sistemlerine Giriş. Milli Ĕ̌̆itim Bakanlı̆̆l, Ankara, 69.
Özer, A. (2016). Endüstriyel Sistemlerde PLC ve SCADA Uygulaması. Yüksek Lisans Tezi, Marmara Üniversitesi Fen Bilimleri Enstitüsü, İstanbul.

Şeker, H. (2019). SCADA Sistemler ve Modbus Güvenlik Açıklıkları.

Yaşar, E. (2020). Bir Tartım Otomasyonunda, Platform Tipi Yük Hücrelerinin, S-tipi Olarak Kullanılması. European Journal of Science and Technology, November, 221-227. https://doi.org/10.31590/ejosat.821620 